\title{
A Bi-Modal Characterization of Epistemic Logic
}

\author{
Arata Isнгмото \\ Tolyo Institute of Technology
}

In now classic 'Knowledge and Belief' (Hintikka [6]) Hintikka analyzed knowing and believing from a standpoint of many-world semantics. More specifically these two intellectual acts were interpreted as two logical operations, which are different, but closely related to each other. It is not difficult to see that knowing and believing respectively behave like the necessity of $\mathrm{S} 4$ of Lewis and that of DS4. (DS4 is the modal propositional logic to be obtained from S4 by replacing the axioms of the form $\square \mathrm{A} \supset \mathrm{A}$ by weaker ones, namely, those having the form $\square \mathrm{A} \supset \supset \mathrm{A}$, i.e., $\square \mathrm{A} \supset \sim \square \sim \mathrm{A}$.)

It is the purpose of the present paper to continue this pioneering work of Hintikka in the field of epistemic logic by more formally characterizing it as a bimodal propositional logic to be designated as S4-DS4, which constitutes a bi-modal combination of S4 and DS4 with the necessity corresponding to S4 (i.e., knowing) stronger than the correspondent of DS4 (i.e., believing). (For bi-modal logics refer to Rubin [14], Fitting [4], Ishimoto-Fujikawa [9], Ishimoto-Watanabe [10] and Ono [13]. The acquaintance with these works is not assumed in what follows, however.)

\$1 Syntactic preliminaries As is usually the case with other types of modal propositional logics the (well-formed) formulas (of proposed S4-DS4) to be designated by such meta-logical variables as $A, B, \cdots$ and the like are defined as the smallest class containing all the propositional variables (atomic formulas) being closed under four logical symbols, namely, $\vee$ (disjunction), $\sim$ (negation), $\square_{1}$ (stronger necessity=knowing) and $\square_{2}$ (weaker necessity=believing) with the help of some technical symbols. The logical symbols other than these, if any, are defined in terms of these symbols in the well-known way.

With a view to simplifying the subsequent development we next define (inductively) the notion of positive and negative parts of a formula after Schütte (Schütte [15], [16], [17], [18], [19]).

Definition 1.1 The positive and negative parts of A are defined only as follows:

$1.11 \mathrm{~A}$ is a positive part of $\mathrm{A}$,

1.12 If $\mathrm{B} \vee \mathrm{C}$ is a positive part of $\mathrm{A}$, then $\mathrm{B}$ and $\mathrm{C}$ are both positive parts of $\mathrm{A}$,

The author greatly acknowledges the help and assistance Professor Akira Ohide of Keio University has given to him in connection with the work to follow. 
1.13 If $\sim \mathrm{B}$ is a positive part of $\mathrm{A}$, then $\mathrm{B}$ is a is a negative part of $\mathrm{A}$,

1.14 If $\sim \mathrm{B}$ is a negstive part of $\mathrm{A}$, then $\mathrm{B}$ is a positive part of $\mathrm{A}$.

(Here as well as in what follows outermost parentheses will be omitted, whenever no ambiguity arises therefrom.)

Again following Schütte such an expression as $F\left[A_{+}\right]\left(G\left[B_{-}\right]\right)$means that the formula $F\left[A_{+}\right]\left(G\left[B_{-}\right]\right.$) contains as a positive (negative) part thereof a specified occurrence of $A(B) . F\left[A_{+}, B_{-}\right], G\left[A, B_{+}\right]$and the like are analogously understood subject to the condition that the specified occurrences of formulas do not overlap with each other.

The minimally positive (negative) parts of a formula are defined to be those positive (negative) parts of the formula, which do not contain properly any positive or negative parts of the formula. Thus atomic formulas as well as the formulas of the form $\square_{1} A$ or $\square_{2} A$ ( $A \vee B, \square_{1} A$ or $\square_{2} A$ ) could be minimally positive (negative) parts of a formula.

Another notion indispensable in the sequel is the removal (Streichung) from a formula of its positive or negative parts. Following Schütte the result of removing $A(B)$ from $F\left[A_{+}\right]\left(G\left[B_{-}\right]\right)$will be denoted by $F\left[{ }_{+}\right]\left(G\left[{ }_{-}\right]\right)$, which is possibly the empty expression.

Definition 1.2 The removal A from $\left.\mathrm{F}\left[\mathrm{A}_{+}\right]\left(\mathrm{G}_{[} \mathrm{A}_{-}\right]\right)$is defined only as follows:

1.21 If $\mathrm{F}\left[\mathrm{A}_{+}\right]$is $\mathrm{A}$, then $\mathrm{F}\left[+_{+}\right]$is the empty expression,

1.22 If $\mathrm{F}_{[}\left[\mathrm{A}_{+}\right]$is $\mathrm{F}_{1}\left[\mathrm{~A} \vee \mathrm{B}_{+}\right]$or $\mathrm{F}_{1}\left[\mathrm{~B} \vee \mathrm{A}_{+}\right]$, then $\mathrm{F}[+]$ is $\mathrm{F}_{1}[+] \vee \mathrm{B}$,

1.23 If $\mathrm{F}\left[\mathrm{A}_{+}\right]$is $\mathrm{F}_{1}\left[\sim \mathrm{A}_{-}\right]$, then $\mathrm{F}[+]$ is $\mathrm{F}_{1}[-]$,

1.24 If $\mathrm{G}\left[\mathrm{A}_{-}\right]$is $\mathrm{G}_{1}\left[\sim \mathrm{A}_{+}\right]$, then $\mathrm{G}[-]$ is $\mathrm{G}_{1}[+]$.

It is not difficult to see that the result of removing a formula from another constitutes a formula or the empty expression.

The removing of a formula thus defined will be illustrated as follows:

$$
\begin{aligned}
& \text { For } \mathrm{F}\left[\mathrm{A}_{+}\right]=\mathrm{F}_{1}\left[\sim \mathrm{A}_{-}\right]=\mathrm{F}_{2}\left[\sim \mathrm{A}_{+}\right] \\
& =\mathrm{F}_{3}\left[\mathrm{~B} \vee \sim \sim \mathrm{A}_{+}\right]=\mathrm{F}_{4}\left[(\mathrm{~B} \vee \sim \sim \mathrm{A}) \vee \mathrm{C}_{+}\right] \\
& =(\mathrm{B} \vee \sim \sim \mathrm{A}) \vee \mathrm{C} \text {, } \\
& \mathrm{F}[+]=\mathrm{F}_{1}[-]=\mathrm{F}_{2}[+]=\mathrm{F}_{3}[+] \vee \mathrm{B} \\
& =\left(\mathrm{F}_{4}[+] \vee \mathrm{C}\right) \vee \mathrm{B}=(\text { the empty expression } \vee \mathrm{C}) \vee \mathrm{B} \\
& =\mathrm{C} \vee \mathrm{B} \text {, } \\
& \text { For } \mathrm{F}\left[\mathrm{A}_{+}\right]=\mathrm{F}_{1}\left[\mathrm{~A} \vee \mathrm{C}_{+}\right]=\mathrm{F}_{2}\left[\sim(\mathrm{A} \vee \mathrm{C})_{-}\right] \\
& =\mathrm{F}_{3}\left[\sim \sim(\mathrm{A} \vee \mathrm{C})_{+}\right]=\mathrm{F}_{4}\left[\mathrm{~B} \vee \sim \sim(\mathrm{A} \vee \mathrm{C})_{+}\right] \\
& =\mathrm{B} \vee \sim \sim(\mathrm{A} \vee \mathrm{C}) \text {, } \\
& \mathrm{F}[+]=\mathrm{F}_{1}[+] \vee \mathrm{C}=\mathrm{F}_{2}[-] \vee \mathrm{C} \\
& =\mathrm{F}_{3}[+] \vee \mathrm{C}=\left(\mathrm{F}_{4}[++] \vee \mathrm{B}\right) \vee \mathrm{C} \\
& =(\text { the empty expression } \vee \mathrm{B}) \vee \mathrm{C}=\mathrm{B} \vee \mathrm{C} \text {, } \\
& \text { For } \mathrm{G}\left[\mathrm{A}_{-}\right]=\mathrm{G}_{1}\left[\sim \mathrm{A}_{+}\right]=\mathrm{G}_{2}\left[\mathrm{C} \vee \sim \mathrm{A}_{+}\right]
\end{aligned}
$$




$$
\begin{aligned}
& =\mathrm{G}_{3}\left[\mathrm{~B} \vee(\mathrm{C} \vee \sim \mathrm{A})_{+}\right]=\mathrm{B} \vee(\mathrm{C} \vee \sim \mathrm{A}), \\
\mathrm{G}[-] & =\mathrm{G}_{1}[+]=\mathrm{G}_{2}[+] \vee \mathrm{C} \\
& =\left(\mathrm{G}_{3}[+] \vee \mathrm{B}\right) \vee \mathrm{C} \\
& =(\text { the empty expression } \vee \mathrm{B}) \vee \mathrm{C}=\mathrm{B} \vee \mathrm{C}, \\
\text { For } \mathrm{G}[\mathrm{A}-] & =\mathrm{G}_{1}\left[\sim \mathrm{A}_{+}\right]=\mathrm{G}_{2}\left[\sim \mathrm{A} \vee \mathrm{B}_{+}\right] \\
& =\mathrm{G}_{3}\left[\sim(\sim \mathrm{A} \vee \mathrm{B})_{-}\right]=\mathrm{G}_{4}\left[\sim \sim(\sim \mathrm{A} \vee \mathrm{B})_{+}\right] \\
& =\sim \sim(\sim \mathrm{A} \vee \mathrm{B}), \\
\mathrm{G}[-] & =\mathrm{G}_{1}[+]=\mathrm{G}_{2}[+] \vee \mathrm{B}=\mathrm{G}_{3}[-] \vee \mathrm{B} \\
& =\mathrm{G}_{4}[+] \vee \mathrm{B}=\text { the empty expression } \vee \mathrm{B} \\
& =\mathrm{B},
\end{aligned}
$$

where the disjunction involving the empty expression is defined in a selfexplanatory way.

We are now in a position to define (Beth) tableaux for the proposed bi-modal logic and with this in view we next introduce a number of reduction rules to be applied to a formula. (Unlike other tableau methods not a set of formulas, but a formula is reduced, and this will have the effect of simplifying the subsequent development.) Nevertheless if we disregard the complexities arising from the notion of positive and negative parts of a formula, such reduction rules are wellknown, and we are here essentially following Smullyan [20] and Schütte [18], the latter being a prototype of our formalism, since it also depends upon the notion of positive and negative parts of a formula.

The proposed reduction rules are applied in one of the following forms:

$$
\begin{aligned}
& \mathrm{V}_{-} \frac{\mathrm{F}\left[\mathrm{A} \vee \mathrm{B}_{-}\right]}{\mathrm{F}\left[\mathrm{A} \vee \mathrm{B}_{-}\right] \vee \sim \mathrm{A} \mid \mathrm{F}\left[\mathrm{A} \vee \mathrm{B}_{-}\right] \vee \sim \mathrm{B}} \text {, } \\
& \square_{1-} \frac{\mathrm{F}\left[\square_{\mathbf{1}} \mathrm{A}_{-}\right]}{\mathrm{F}\left[\square_{1} \mathrm{~A}_{-}\right] \vee \sim \mathrm{A}} \text {, } \\
& \square_{1+} \frac{F\left[\square_{1} A_{1-}, \square_{1} A_{2^{-}}, \cdots \square_{1} A_{n-}, \square_{1} B_{+}\right]}{\sim \square_{1} A_{1} \vee \sim \square_{1} A_{2} \vee \cdots \vee \sim \square_{1} A_{n} \vee B}, \\
& \square_{2}+\frac{F\left[\square_{i_{1}} A_{1^{-}}, \square_{i_{2}} A_{2-}, \cdots, \square_{i_{n}} A_{n-}, \square_{2} B_{+}\right]}{\sim \square_{i_{2}} A_{1} \vee \sim \square{i_{2}}_{2} A_{2} \vee \cdots \vee \sim \square i_{i_{n}} A_{n} \vee \sim A_{j_{1}} \vee \sim A_{j_{2}} \vee \cdots \vee \sim A_{j_{m}} \vee B} \text {, }
\end{aligned}
$$

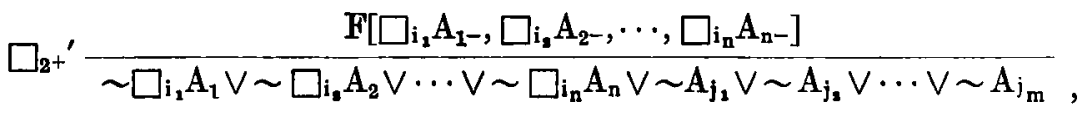

where in the application of $\square_{1+}$ or $\square_{2+}\left(\square_{2+}{ }^{\prime}\right) 0 \leq n(0<n)$ and disjunctions with more than two disjuncts are associated in any way. Further in the application of $\square_{2+}$ or $\square_{2+}{ }^{\prime} \square_{i_{k}} A_{k}$ 's are $\square_{1} A_{k}$ or $\square_{2} A_{k}$, while only for those $\square_{i_{k}} A_{k}$ 's with $i_{k}=$ $2 \sim A_{k}$ is adjoined to the reductum. It is also required that in the application of 
$\square_{2+}{ }^{\prime}$ at least one $\square_{i_{k}} A_{k}$ is $\square_{2} A_{k}$ and there is no formula occurring positively in the formula to be reduced with the form $\square_{2} A$. (In such an event the reduction will be taken over by $\left.\square_{2+}\right)$. We, thus, have $0<\mathrm{m}$, The case $\mathrm{m}=0$ is covered by $\square_{1-}$.

It is further stipulated that in the application of $\square_{1+}, \square_{2+}$ or $\square_{2+}{ }^{\prime} \square_{1} \mathbf{A}_{\mathbf{k}}$ and $\square i_{k} A_{k}$ 's are exhaustive in the sense that there are no formulas remaining in the formula to be reduced with specified forms, but not involved explicitly in the reduction. Thus,

$$
\frac{\sim \square_{1} A_{1} \vee \sim \square_{2} A_{2} \vee \square_{2} B \vee C}{\sim \square_{2} A_{2} \vee \sim A_{2} \vee B}
$$

is not a correct application of $\square_{2+}$. It should be applied thus:

$$
\square_{2+} \frac{\sim \square{ }_{1} A_{1} \vee \sim \square_{2} A_{2} \vee \square_{2} B \vee C}{\sim \square A_{1} A_{1} \vee \sim \square \square_{2} A_{2} \vee \sim A_{2} \vee B},
$$

where $\mathrm{C}$ is atomic.

It is also not difficult to see that there are $n$ ways of reducing a formula by $\square_{1+}\left(\square_{2+}\right)$, if the formula to be reduced contains $n$ positive occurrences of $\square_{1} B$ $\left(\square_{\mathrm{2}} \mathrm{B}\right)$.

Now a configuration is defined to be a finite set of formulas. Upon applying one of the reduction rules to any constituent formula of a configuration we obtain another configuration by replacing the formula by the result or results (in the case of a branching rule, i.e., $V_{-}$) of the application of the rule. A tableau is, then, a finite sequence of such configurations, any member configuration of which except the leftmost is obtained from one of the preceding configurations by the application of a reduction rule. A tableau is said to be closed if some member configuration thereof is such that every constituent formula is of the form $F\left[A_{+}, A_{-}\right]$.

Given a formula $A$ and a closed tableau beginning with $[A]$ the tableau constitutes a proof of $\mathrm{A}$ and $\mathrm{A}$ is a thesis of S4-DS4 (in the tableau method).

For illustrative purposes some theses will be proved by the proposed tableau method:

1.31 The proof of $\square_{1} A \supset \square_{2} A$, i.e., $\sim \square_{1} A \vee \square_{2} A$ :

$$
\begin{array}{ll}
\left\{\sim \square_{1} A \vee \square_{2} A\right\} & \\
\left\{\sim \square_{1} A \vee A\right\} & \text { by } \square_{2^{+}}, \\
\left\{\sim \square_{1} A \vee A \vee \sim A\right\} & \text { by } \square_{1^{-}} .
\end{array}
$$

1.32 The proof of $\square_{1}(A \supset B) \supset\left(\square_{1} A \supset \square_{1} B\right)$, i.e., $\sim \square_{1}(\sim A \vee B) \vee \sim \square_{1} A \vee \square_{1} B$ :

$$
\begin{aligned}
& \left\{\sim \square_{1}(\sim A \vee B) \vee \sim \square_{1} A \vee \square_{1} B\right\} \\
& \left\{\sim \square_{1}(\sim A \vee B) \vee \sim \square_{1} A \vee B\right\} \\
& \left\{\sim \square_{1}(\sim \mathrm{A} \vee \mathrm{B}) \vee \sim \square_{1} \mathrm{~A} \vee \mathrm{B} \vee \sim(\sim \mathrm{A} \vee \mathrm{B})\right\} \\
& \left\{\sim \square_{1}(\sim A \vee B) \vee \sim \square_{1} A \vee B \vee \sim(\sim A \vee B) \vee \sim A\right\} \\
& \left(\sim \square_{1}(\sim A \vee B) \vee \sim \square_{1} A \vee B \vee \sim(\sim A \vee B) \vee \sim A \vee \sim \sim A\right. \text {, } \\
& -138-
\end{aligned}
$$




$$
\left.\sim \square_{1}(\sim \mathrm{A} \vee \mathrm{B}) \vee \sim \square_{1} \mathrm{~A} \vee \mathrm{B} \vee \sim(\sim \mathrm{A} \vee \mathrm{B}) \vee \sim \mathrm{A} \vee \sim \mathrm{B}\right) \quad \text { by } \vee-.
$$

1.33 The proof of $\square_{2}(\mathrm{~A} \supset \mathrm{B}) \supset\left(\square_{2} \mathrm{~A} \supset \square_{2} \mathrm{~B}\right)$, i.e., $\sim \square_{2}(\sim \mathrm{A} \vee \mathrm{B}) \vee \sim \square_{2} \mathrm{~A} \vee \square_{2} \mathrm{~B}$ :

$$
\begin{aligned}
& \left\{\sim \square_{2}(\sim \mathrm{A} \vee \mathrm{B}) \vee \sim \square_{2} \mathrm{~A} \vee \square_{2} \mathrm{~B}\right\} \\
& \left(\sim \square_{2}(\sim A \vee B) \vee \sim \square_{2} A \vee \sim(\sim A \vee B) \vee \sim A \vee B\right\} \quad \text { by } \square_{2}+ \\
& \left\{\sim \square_{2}(\sim A \vee B) \vee \sim \square_{2} A \vee \sim(\sim A \vee B) \vee \sim A \vee B \vee \sim \sim A\right. \text {, } \\
& \left.\sim \square_{2}(\sim A \vee B) \vee \sim \square_{2} A \vee \sim(\sim A \vee B) \vee \sim A \vee B \vee \sim B\right\} \text { by } \vee-.
\end{aligned}
$$

1.34 The proof $\square_{1} A \supset A$, i.e., $\sim \square_{1} A \vee A$ :

$$
\begin{aligned}
& \left\{\sim \square_{1} A \vee A\right\} \\
& \left\{\sim \square_{1} A \vee A \vee \sim A\right\} \quad \text { by } \square_{1^{-}} .
\end{aligned}
$$

1.35 The proof of $\square_{2} A \supset \sim \square_{2} \sim A$, i.e., $\sim \square_{2} A \vee \sim \square_{2} \sim A$, or, $\square_{2} A \supset \diamond_{2} A$ :

$$
\begin{aligned}
& \left\{\sim \square_{2} A \vee \sim \square_{2} \sim A\right\} \\
& \left\{\sim \square_{2} A \vee \sim \square_{2} \sim A \vee \sim A \vee \sim \sim A\right\}
\end{aligned}
$$

1.36 The proof of $\square_{1} A \supset \square_{1} \square_{1} A$, i.e., $\sim \square_{1} A \vee \square_{1} \square_{1} A$ :

$$
\begin{aligned}
& \left\{\sim \square_{\mathbf{1}} \mathrm{A} \vee \square_{1} \square_{\mathbf{1}} \mathrm{A}\right\} \\
& \left\{\sim \square_{\mathbf{1}} \mathrm{A} \vee \square_{1} \mathrm{~A}\right\}
\end{aligned}
$$

1.37 The proof of $\square_{2} A \supset \square_{2} \square_{2} A$, i.e., $\sim \square_{2} A \vee \square_{2} \square_{2} A$ :

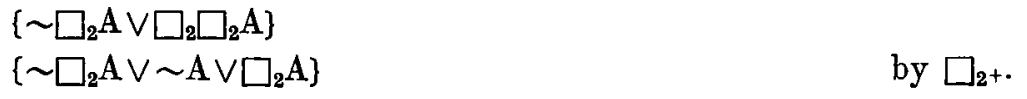

1.38 The proof of $\square_{2} A \supset\left(\square_{2} B \supset \square_{2}(A \wedge B)\right)$, i.e., $\sim \square_{2} A \vee \sim \square_{2} B \vee \square_{2} \sim(\sim A \vee$ $\sim \mathrm{B})$ :

$$
\begin{array}{ll}
\left\{\sim \square_{2} A \vee \sim \square_{2} B \vee \square_{2} \sim(\sim A \vee \sim B)\right\} & \\
\left\{\sim \square{ }_{2} A \vee \sim \square_{2} B \vee \sim A \vee \sim B \vee \sim(\sim A \vee \sim B)\right\} & \text { by } \square_{2+}, \\
\left\{\sim \square_{2} A \vee \sim \square_{2} B \vee \sim A \vee \sim B \vee \sim(\sim A \vee \sim B) \vee \sim \sim A,\right. & \\
\left.\sim \square_{2} A \vee \sim \square_{2} B \vee \sim A \vee \sim B \vee \sim(\sim A \vee \sim B) \vee \sim \sim B\right\} & \text { by } V_{-} .
\end{array}
$$

1.39 The proof of $\square_{2}(A \wedge B) \supset\left(\square_{2} A \wedge \square_{2} B\right)$, i.e., $\sim \square_{2} \sim(\sim A \vee \sim B) \vee$ $\sim\left(\sim \square_{2} \mathrm{~A} \vee \sim \square_{2} \mathrm{~B}\right)$ :

$$
\begin{array}{ll}
\left\{\sim \square_{2} \sim(\sim A \vee \sim B) \vee \sim\left(\sim \square_{2} A \vee \sim \square_{2} B\right)\right\} & \\
\left\{\sim \square_{2} \sim(\sim A \vee \sim B) \vee \sim\left(\sim \square_{2} A \vee \sim \square_{2} B\right) \vee \sim \sim \square_{2} A,\right. & \\
\left.\sim \square_{2} \sim(\sim A \vee \sim B) \vee \sim\left(\sim \square_{2} A \vee \sim \square_{2} B\right) \vee \sim \sim \square_{2} B\right\} & \text { by } V_{-}, \\
\left\{\sim \square_{2} \sim(\sim A \vee \sim B) \vee \sim \sim(\sim A \vee \sim B) \vee A,\right. & \\
\left.\sim \square_{2} \sim(\sim A \vee \sim B) \vee \sim\left(\sim \square_{2} A \vee \sim \square_{2} B\right) \vee \sim \sim \square_{2} B\right\} & \text { by } \square_{2^{+}}, \\
\left\{\sim \square_{2} \sim(\sim A \vee \sim B) \vee \sim \sim(\sim A \vee \sim B) \vee A,\right. & \\
\left.\sim \square_{2} \sim(\sim A \vee \sim B) \vee \sim \sim(\sim A \vee \sim B) \vee B\right\} & \text { by } \square \square_{2} .
\end{array}
$$

$\S 2$ Semantics We are now in a position to introduce a Kripke-type semantics or models of the proposed S4-DS4. The model M of S4-DS4 is a quadruple $\left\langle G, R_{1}\right.$, $R_{2}, \Leftrightarrow$ to be defined on a model structure $\left\langle G, R_{1}, R_{2}\right\rangle$ satisfying the following conditions: 
$2.11 \mathrm{G}$ is a non-empty set (of possible worlds),

$2.12 R_{1}$ is a reflexive and transitive relation defined on $G$,

$2.13 R_{2}$ is a transitive relation defined on $G$,

$2.14 \forall \Gamma \Delta\left(\Gamma \mathrm{R}_{2} \Delta \Rightarrow \Gamma \mathrm{R}_{1} \Delta\right)$,

$2.15 \forall \Gamma \exists \Delta \Gamma \mathrm{R}_{2} \Delta$,

where $\Gamma, \Delta, \cdots$ and the like are meta-logical variables ranging over the elements of $\mathrm{G}$,

$2.16 \vDash$ is a (satisfaction) relation between the elements of $G$ and atomic formulas.

On the basis of 2.16 the (satisfaction) relation $\models$ is (uniquely) extended to any element $\Gamma$ of $\mathrm{G}$ and formulas as follows:

$2.21 \Gamma \models \mathrm{A} \vee \mathrm{B} \Leftrightarrow . \Gamma \models \mathrm{A}$ or $r \models \mathrm{B}$,

$2.22 \Gamma \models \sim \mathrm{A} \Leftrightarrow \Gamma \not \models \mathrm{A}(\operatorname{not} \Gamma \vDash \mathrm{A})$,

$2.23 \Gamma \models \square_{1} \mathrm{~A} \Leftrightarrow \forall \Delta\left(\Gamma \mathrm{R}_{1} \Delta \Rightarrow \Delta \models \mathrm{A}\right)$,

$2.24 \Gamma \models \square_{2} \mathrm{~A} \Leftrightarrow \forall \Delta\left(\Gamma \mathrm{R}_{2} \Delta \Rightarrow \Delta=\mathrm{A}\right)$.

A formula $A$ is valid in a model $M=\left\langle G, R_{1}, R_{2}, \models\right\rangle$ if for every $\Gamma \in G \quad \Gamma \models A$. A is valid if it is valid in every model. $A$ is, thus, not valid, namely, refutable iff there is a model $\mathrm{M}=\left\langle\mathrm{G}, \mathrm{R}_{1}, \mathrm{R}_{2}, \models\right\rangle$ and a $\Gamma \in \mathrm{G}$ such that $\Gamma \not \models \mathrm{A}$, i.e., $\Gamma \models \sim \mathrm{A}$.

Lemma 2.31 Given a model $\mathrm{M}=\left\langle\mathrm{G}, \mathrm{R}_{1}, \mathrm{R}_{2}, \models\right\rangle$ and a $\Gamma \in \mathrm{G}$, if $\Gamma \models \sim \mathrm{F}\left[\mathrm{A}_{+}\right]$ $\left(\Gamma \models \sim \mathrm{G}\left[\mathrm{A} \_\right]\right)$, then $\Gamma \models \sim \mathrm{A}(\Gamma \models \mathrm{A})$.

These two assertions are proved simultaneously by induction on the basis of Definition 1.1 for specifying the positive and negative parts of a formula.

The basis is straightforward, while induction steps are taken care of in the following way:

$$
\begin{aligned}
\Gamma \models & \sim \mathrm{F}\left[\mathrm{A}_{+}\right]\left(=\sim \mathrm{F}_{1}\left[\mathrm{~A} \vee \mathrm{B}_{+}\right] \text {or }=\sim \mathrm{F}_{1}\left[\mathrm{~B} \vee \mathrm{A}_{+}\right]\right) \\
& \Rightarrow \Gamma \models \sim(\mathrm{A} \vee \mathrm{B})(\mathrm{or} \sim(\mathrm{B} \vee \mathrm{A})) \Rightarrow \Gamma \models \sim \mathrm{A}, \\
\Gamma \models \sim \mathrm{F}\left[\mathrm{A}_{+}\right]\left(=\sim \mathrm{F}_{1}\left[\sim \mathrm{A}_{-}\right]\right) \Rightarrow \Gamma \models \sim \mathrm{A}, & \left.\Rightarrow \quad r=\sim \mathrm{G}_{-}\right]\left(=\sim \mathrm{G}_{1}\left[\sim \mathrm{A}_{+}\right]\right) \\
& \Rightarrow \Gamma \models \sim \sim \mathrm{A} \Leftrightarrow \Gamma \models \mathrm{A} .
\end{aligned}
$$

Lemma 2.32 If a formula is not valid, i.e., refutable, then the formula, which obtains therefrom as a result of the applciation of a reduction rule (at least one formula in the case of a branching rule) is also not valid.

Suppose $\Gamma \models \sim F\left[A \vee B_{-}\right]$for $M=\left\langle G, R_{1}, R_{2}, \models\right\rangle$ and $r \in G$. By Lemma 2.31 $\Gamma \models \mathrm{A} \vee \mathrm{B}$. Thus $\Gamma \models \mathrm{A}$ or $\Gamma \models \mathrm{B}$ by 2.21. If $\Gamma \models \mathrm{A}$, then $\Gamma \models \sim\left(\mathrm{F}\left[\mathrm{A} \vee \mathrm{B}_{-}\right] \vee \sim \mathrm{A}\right)$, which is nothing but the refutability of $\mathrm{F}\left[\mathrm{A} \vee \mathrm{B}_{-}\right] \vee \sim \mathrm{A}$. The case that $\Gamma=\mathrm{B}$ is taken care of analogously.

Let $r \models \sim \mathrm{F}\left[\square_{1} \mathrm{~A}_{-}\right]$for $\mathrm{M}=\left\langle\mathrm{G}, \mathrm{R}_{1}, \mathrm{R}_{2}, \models\right\rangle$ and $\Gamma \in \mathrm{G}$. By Lemma 2.31 $\Gamma \models$ $\square_{1} A$. In view of 2.23 and the reflexivity of $R_{1}$ we have $\Gamma \models A$. From this follows $\Gamma \models \sim\left(\mathrm{F}\left[\square_{1} \mathrm{~A}_{-}\right] \vee \sim \mathrm{A}\right)$ and $\mathrm{F}\left[\square_{1} \mathrm{~A}\right] \vee \sim \mathrm{A}$ is refutable. 
Suppose, next, $\Gamma \models \sim F\left[\square_{1} A_{1^{-}}, \square_{1} A_{2^{-}}, \cdots \square_{1} A_{n^{-}}, \square_{1} B_{+}\right]$(with $0<\mathrm{n}$ ) for $M=$ $\left\langle\mathrm{G}, \mathrm{R}_{1}, \mathrm{R}_{2}, \models\right.$ and $\Gamma \in \mathrm{G}$. By Lemma 2.31 $\Gamma \models \square_{1} \mathrm{~A}_{1}, \Gamma \models \square_{1} \mathrm{~A}_{2}, \cdots, \Gamma \models \square_{1} \mathrm{~A}_{\mathrm{n}}$, and $\Gamma \models \sim \square_{1} \mathrm{~B}$, the last of which gives rise to $\Delta \models \sim B$ for a $\Delta \in G$ such that $r R_{1} \Delta$ in view of 2.22 and 2.23. In view of 2.23 and the trasitivity of $\mathrm{R}_{1}$ from $I \models \square_{1} \mathrm{~A}_{1}$, $\Gamma \models \square_{1} \mathrm{~A}_{2}, \cdots$, and $\Gamma \models \square_{1} \mathrm{~A}_{\mathrm{n}}$ obtain respectively $\Delta \models \square_{1} \mathrm{~A}_{1}, \Delta \models \square_{1} \mathrm{~A}_{2}, \cdots$, and $\Delta \models \square_{1} A_{n}$, which together with $\Delta \models \sim B$ yield in conjunction the refutability of $\sim \square_{1} A_{1} \vee \sim \square_{1} A_{2} \vee \cdots \vee \sim \square_{1} A_{n} \vee B$. The case that $n=0$ is taken care of analogously.

The cases respectively corresponding to $\square_{2+}$ and $\square_{2+}{ }^{\prime}$ will be illustrated by examples:

Let us assume $\Gamma \not K C_{1} \vee \sim \square_{2} A_{1} \vee C_{2} \vee \sim \square_{1} A_{2} \vee \square_{2} B \vee \sim \square_{2} A_{3} \vee C_{3}$ for $M=\langle G$, $\mathrm{R}_{1}, \mathrm{R}_{2}, \models>$ and $\Gamma \in \mathrm{G}$ with $\mathrm{C}_{1}, \mathrm{C}_{2}$ and $\mathrm{C}_{3}$ not of the form $\mathrm{F}\left[\square_{1} \mathrm{~A}_{-}\right]$or $\mathrm{F}\left[\square_{2} \mathrm{~A}_{-}\right]$. By Lemma 2.31 we, then, have $\Gamma \models \square_{2} \mathrm{~A}_{1}, \Gamma \models \square_{1} \mathrm{~A}_{2}, \Gamma \models \square_{2} \mathrm{~A}_{3}$ and $\Gamma \models \sim \square_{2} \mathrm{~B}$, from the last of which obtains $\Delta \models \sim B$ for a $\Delta \in \mathrm{G}$ such that $r \mathrm{R}_{2} \Delta$ by 2.22 and 2.24 . In view of 2.23 and 2.24 as well as of 2.14 and the transitivity of $R_{1}$ and $R_{2}$ we have $\Delta \models \square_{2} \mathrm{~A}_{1}, \Delta \models \square_{1} \mathrm{~A}_{2}, \Delta \models \square_{2} \mathrm{~A}_{3}, \Delta \models \mathrm{A}_{1}$ and $\Delta \models \mathrm{A}_{3}$, which along with $\Delta \models \sim \mathrm{B}$ give rise to the refutability of $\sim \square_{2} A_{1} \vee \sim \square_{1} A_{2} \vee \sim \square_{2} A_{3} \vee \sim A_{1} \vee \sim A_{3} \vee B$ as required.

Lastly for taking care of $\square_{2+}{ }^{\prime}$ suppose $\Gamma \not k C_{1} \vee \sim \square_{1} A_{1} \vee \sim \square_{2} A_{2} \vee \sim \square_{2} A_{3} \vee C_{2}$ for $\mathrm{M}=\left\langle\mathrm{G}, \mathrm{R}_{1}, \mathrm{R}_{2}, \models\right\rangle$ and $\Gamma \in \mathrm{G}$, where $\mathrm{C}_{1}$ and $\mathrm{C}_{2}$ are not of the form $\mathrm{F}\left[\square_{1} \mathrm{~A}_{-}\right]$, $\mathrm{F}\left[\square_{2} \mathrm{~A}_{-}\right]$or $\mathrm{F}\left[\square_{2} \mathrm{~A}_{+}\right]$. By Lemma 2.31 we, then, have $\Gamma \models \square_{1} \mathrm{~A}_{1}, \Gamma \models \square_{2} \mathrm{~A}_{2}$ and $\Gamma \models \square_{2} \mathrm{~A}_{3}$. In view of 2.15 there is a $\Delta \in \mathrm{G}$ such that $\Gamma \mathrm{R}_{2} \Delta$, which in turn gives rise to $\Gamma \mathrm{R}_{1} \Delta$ by 2.14. In view of 2.23 and 2.24 as well as of the transitivity of $R_{1}$ and $R_{2}$ from these follow $\Delta \models \square_{1} A_{1}, \Delta \models \square_{2} A_{2}, \Delta \models \square_{2} A_{3}, \Delta \models A_{2}$ and $\Delta \models A_{3}$, which together yield the looked-for refutability of $\sim \square_{1} A_{1} \vee \sim \square_{2} A_{2} \vee \sim \square_{2} A_{3} \vee$ $\sim \mathrm{A}_{2} \vee \sim \mathrm{A}_{3}$.

This completes the proof of Lemma 2.32.

Lemma 2.4 (Consistency theorem) If $\mathrm{A}$ is provable, then $\mathrm{A}$ is valid.

Suppose, if possible, that $A$ be provable, but not valid. We, then, have a model $\mathrm{M}=\left\langle\mathrm{G}, \mathrm{R}_{1}, \mathrm{R}_{2}, \models\right\rangle$ and a $\Gamma \in \mathrm{G}$ such that $\Gamma \models \sim \mathrm{A}$. Since $\mathrm{A}$ is a thesis there is a closed tableau beginning with $\{A\}$. In view of Lemma 2.32 this would mean that a formula of the form $\mathrm{F}\left[\mathrm{A}_{+}, \mathrm{A}_{-}\right]$be refutable. But this is against Lemma 2.31 .

With a view to establishing the converse of Lemma 2.4 just proved a Hintikka collection of formulas will be introduced essentially following Smullyan [20]:

Definition 2.5 A Hintikka collection of formulas is a non-empty set W of formulas satisfying the following conditions:

For any $\mathbf{F} \in \mathrm{W}$,

2.51 No formula occurs in $\mathrm{F}$ simultaneously as its positive and negative part, $2.52 \mathrm{~A} \vee \mathrm{B}$ is a negative part of $\mathrm{F}$. 
$\Rightarrow$ : A is a negative part of $\mathrm{F}$.

or. $\mathrm{B}$ is a negative part of $\mathrm{F}$,

$2.53 \square_{1} \mathrm{~A}$ is a positive part of $\mathrm{F}$.

$\Rightarrow \exists \mathrm{G}\left(\mathrm{F} \mathrm{R}_{1} \mathrm{G}\right.$ and $\mathrm{A}$ is a positive part of $\left.\mathrm{G}\right)$,

$2.54 \square_{1} \mathrm{~A}$ is a negative part of $\mathrm{F}$.

$\Rightarrow \cdot \mathrm{A}$ is a negative part of $\mathrm{F}$,

$2.55 \square_{2} \mathrm{~A}$ is a positive part of $\mathrm{F}$. $\Rightarrow \exists \mathrm{G}\left(\mathrm{F} \mathrm{R}_{2} \mathrm{G}\right.$ and $\mathrm{A}$ is a positive part of $\left.\mathrm{G}\right)$,

$2.56 \square_{2} \mathrm{~A}$ is a negative part of $\mathrm{F} . \Rightarrow \exists G \quad \mathrm{~F} \mathbf{R}_{2} \mathrm{G}$,

where $R_{1}$ and $R_{2}$ are defined on $W$ as follows:

$\mathrm{F} \mathrm{R}_{1} \mathrm{G} \Leftrightarrow \cdot\left\{\square_{1} \mathrm{~A}: \square_{1} \mathrm{~A}\right.$ is a negative part of $\left.\mathrm{F}\right\}$

$\subseteq\{\mathrm{B}: \mathrm{B}$ is a negative part of $\mathrm{G}\}$,

F $R_{2} G \Leftrightarrow \cdot\left\{\square_{1} A: \square_{1} A\right.$ is a negative part of $\left.F\right\}$

$\cup\left\{\square_{2} \mathrm{~A}: \square_{2} \mathrm{~A}\right.$ is a negative part of $\left.\mathrm{F}\right\}$

$\cup\left\{\mathrm{A}: \square_{\mathbf{2}} \mathrm{A}\right.$ is a negative part of $\left.\mathrm{F}\right\}$

$\subseteq\{\mathrm{B}: \mathrm{B}$ is a negative part of $\mathrm{G}\}$.

Here as well as in what follows such letters as F, G, .... will be employed as meta-logical variables ranging over the elements of a Hintikka collection (of formulas), which, as will be seen presently, will play the role of possible worlds.

It is further stipulated that we shall identify the member formulas of a Hintikka collection having the same set of positive parts (and consequently negative parts). As is easily seen this identification is compatible with the above definition of two accessibility relations.

It is noticed in passing that a Hintikka collection is in existence as will be seen presently.

On the basis of the model structure $\left\langle W, R_{1}, R_{2}\right\rangle F=A$ is defined to be the occurrence of $A$ in $F$ as a negative part for any $F \in G$ and atomic $A$. In view of 2.51 this is consistently carried out in the sense that $F \models A$ or $F \nvdash A$, but not both for any $F \in G$ and atomic $A$. The satisfaction relation $\models$ thus defined is, then, (uniquely and consistently) extended to any $\mathrm{F} \in \mathrm{W}$ and formula by way of 2.21-2.24.

Lemma 2.6 The model $\mathrm{M}=\left\langle\mathrm{W}, \mathrm{R}_{1}, \mathrm{R}_{2}, \models\right\rangle$ thus defined constitutes a model of S4-DS4 satisfying the following for any $\mathrm{F} \in \mathrm{W}$ and $\mathrm{A}$ :

$2.61 \mathrm{~A}$ is a negative part of $\mathrm{F} . \Rightarrow \mathrm{F} F \mathrm{~A}$.

$2.62 \mathrm{~A}$ is a positive part of $\mathrm{F} . \Rightarrow \mathrm{F} \not \models \mathrm{A}$, i.e., $\mathrm{F} \models \sim \mathrm{A}$.

The model $\mathrm{M}$ obviously satsifies 2.11 , since a Hintikka collection is not empty by definition. The reflexivity of $R_{1}$ is forthcoming from its definition. The transitivity of $R_{1}$ and $R_{2}$ also follows from their definitions. This is the same with 2.14. For proving 2.15 let us assume there be a formula of the form $\square_{2} \mathrm{~A}$ occurring in $F$ as a negative part. By 2.56 there is a $G(\epsilon W)$ such that $F R_{2} G$. In case there does not occur in $F$ such a formula, $F R_{2} F$ by the definition of $R_{2}$. Lastly 2.16 
does not present any difficulties.

Now 2.61 and 2.62 are proved simultaneously by induction on the length of $A$, the basis having been taken care of by the definition of $\models$ :

$$
\begin{aligned}
F=F_{1}\left[A_{1} \vee A_{2+}\right] & \Rightarrow F \models \sim A_{1} \text { and } F \models \sim A_{2} . \\
& \Leftrightarrow F \models \sim\left(A_{1} \vee A_{2}\right), \\
F=F_{1}\left[A_{1} \vee A_{2-}\right] & \Rightarrow: A_{1} \text { is a negative part of } F . \\
& \Rightarrow \text { or. } A_{2} \text { is a negative part of } F . \\
& \Rightarrow F \models A_{1} \text { or } F \models A_{2} \cdot \Leftrightarrow F \models A_{1} \vee A_{2}, \\
F=F_{1}\left[\sim A_{1+}\right] & \Rightarrow F \models A_{1} \Leftrightarrow F \models \sim \sim A_{1}, \\
F=F_{1}\left[\sim A_{1-}\right] & \Rightarrow F \models \sim A_{1}, \\
F=F_{1}\left[\square_{1} A_{1+}\right] & \Rightarrow \exists G\left(F R_{1} G \text { and } G=G_{1}\left[A_{+}\right]\right) \\
& \Rightarrow \exists G\left(F R_{1} G \text { and } G \models \sim A_{1}\right) \\
& \Leftrightarrow F \models \sim \square_{1} A_{1}, \\
F=F_{1}\left[\square_{1} A_{1-}\right] & \Rightarrow \forall G\left(F R_{1} G \Rightarrow G=G_{1}\left[A_{1-}\right]\right) \\
& \Rightarrow \forall G\left(F R_{1} G \Rightarrow G \models A_{1}\right) \\
& \Leftrightarrow F \models \square A_{1}, \\
F=F_{1}\left[\square_{2} A_{1+}\right] & \Rightarrow \exists G\left(F R_{2} G \text { and } G=G_{1}\left[A_{1+}\right]\right) \\
& \Rightarrow \exists G\left(F R_{2} G \text { and } G \models \sim A_{1}\right) \\
& \Leftrightarrow F \models \sim \square_{2} A_{1}, \\
F=F_{1}\left[\square_{2} A_{-}\right] & \Rightarrow \forall G\left(F R_{2} G \Rightarrow G=G_{1}\left[A_{1-}\right]\right) \\
& \Rightarrow \forall G\left(F R_{2} G \Rightarrow G \models A_{1}\right) \\
& \Leftrightarrow F \models \square]_{2} A
\end{aligned}
$$

where use is made of Definition 1.1, 2.21-2.24 and the properties of a Hintikka collection including those of accessibility relations.

With a view to proving the completeness theorem let us assume $A$ be not provable.

Given $A$ we are reducing it by $V_{-}$or $\square_{1_{-}}$. If $V_{-}$is applied, at least one of the results of the reduction is not provable, since in the contrary case $A$ would be provable. If $\square_{1-}$ is applied, the result also remains not provable. Repeating such reductions a finite number of times we come eventually across a formula $A_{1}$ called the reduced form of $A$, and any application thereto of $V_{-}$or $\square_{1-}$ does not yield any essentially different formula, if we choose the same formula in the applications of $V_{-}$as before. Here two formulas are essentially the same if the respective sets of their positive (and consequently negative) parts are identical settheoretically. (The member formulas of a Hintikka collection are identical if they are essentially the same.)

A formula with the reduced form or a reduced formula is reached after a finite number of reductions, since there are only a finite number of subformulas of $A$ and only some of them, possibly, coupled with negation could become a disjunct of $A_{1}$, which, however, cannot be extended indefinitely by the applications of V-and $\square$-, 
if we indentify essentially the same formulas. If $A$ is not provable, so is $A_{1}$, of course. (Given $\mathrm{A} \mathrm{A}_{1}$ is not uniquely defined in the presence of a branching rule even if we identify essentially the same formulas:)

It is noticed in passing that in the process of reduction $V_{-}$and $\square_{1-}$ are applied in any order giving rise to essentially the same reduced formula, if a formula is selected properly in the applciation of $V_{-}$, which is a branching rule.

$A_{1}$, which is a reduced form of $A$, is, then, subject to another kind of reductions, namely, $\square_{1+}, \square_{2+}$ or $\square_{2+}$. If $A_{1}$ contains $n$. and $m$ occurrences of $\square_{1} A^{\prime}$ s and $\square_{2}$ A's as positive parts, the reductions by $\square_{1+}$ and $\square_{2+}$ respectively give rise to $n$ and $m$ formulas, which constitute the results of the reductions. If $A_{1}$ contains any occurrence of a formula of the form $\square_{2} A$ as a negative.part, $A_{1}$ without involving the formula of the same form positively is feasible to the reduction by $\square_{2+}$ giving rise to a formula, which is the result of the reduction. The tree of reduction is, thus, ramified into $m+n$.branches if the former is the case, while it is into $n+1$ branches in the latler case.

Each of these formulas, which are not provable, is again subject to the reductions by $V_{-}$and $\square_{1^{-}}$, possibly, giving rise to a reduced formula to be reduced by $\square_{1+}, \square_{2+}$ or $\square_{2+}{ }^{\prime}$.

Such a process of reduction, however, can not be continued indefinitely and we come sooner or later across formulas, to which any reduction yields only the essentially the same formula as one of the previously obtained. This is again because of a finite number of subformulas contained in the formula to be reduced.

Now it is not difficult to see that the (finite) collection $W$ of reduced formulas obtained in the above process of reductions constitutes a Hintikka collection of formulas with essentially the same formulas identified and two accessibility relations between reduced formulas defined as in Definition 2.5. In fact all the properties to be satisfied by a Hintikka collection easily follows from the above construction.

Since the given $A$ constitutes a positive part of a reduced form $F(\in W)$ of $A$, $\mathrm{F} \nvdash \mathrm{A}$ by 2.62 .

This completes the proof of the completeness of our S4-DS4 with respect to the semantics as introduced at the beginning of this section, namely,

Lemma 2.7 (Completeness theorem) If $\mathrm{A}$ is valid, then $\mathrm{A}$ is provable.

Combining Lemmas 2.4 and 2.7 we have,

Theorem 2.8 (Consistency and completeness theorem) $\mathrm{A}$ is provable iff it is valid.

Corollary 2.9 (Separation theorem) If a formula not involving $\square_{2}(\square$ ) is a thesis of S4-DS4, then it is already provable in S4 (DS4).

This is obvious, since the tableau, which constitutes a proof of the formula, turns out to be one in S4 (DS4). In fact the reduction rules employed in the 
proof are those for S4 (DS4). (For such rules refer to Schüte [18] and: Fitting [3].)

In view of Lemma 2.7, if a formula is refutable at all, it is already falsified by a finite model. From this it immediately follows- that S4-DS4 has a finite model property being decidable. In fact, for deciding the thesishood of a given formula it is sufficient to reduce the formula in every possible way, and there are only a finite number of them.

As is expected S4-DS4 is also feasible to Gentzen-type formulation as shown by Uchida [21].

§3 Examples of refutation In this section the method of constructing a Hintikka collection used for the proof of completeness will be employed for falsifying a number of formulas. (In what follows the metalogical variables involved are assumed to be atomic.)

3.1 The refutation of $\square_{2} A \supset \square_{1} A$, i.e., $\sim \square_{2} A \vee \square_{1} A$ :

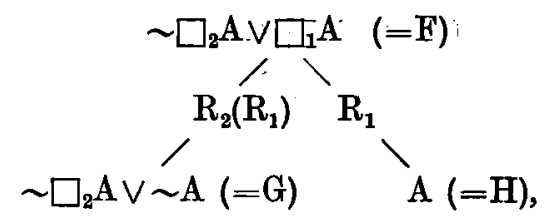

where the Hintikka collection consists of $F$, G'and $H$ l with $F R_{1} F, F R_{1} H, H R_{1} H$, $H R_{2} H, F R_{2} G, F R_{1}, G R_{2} G$ and $G R_{1} G$, and $A$ is true (fasle) in $G(H)$.

3.2 The refutation of $\square_{2} A \supset A$, i.e., $\sim \square_{2} A \vee A$ :

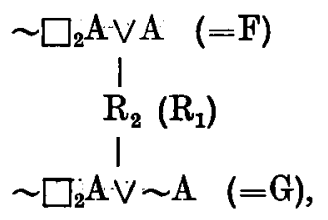

where the Hintikka collection consists of $F$ and $G$ with $F R_{2} G, F R_{1} F, F R_{1} G$, $G R_{1} G$ and $G R_{2} G$, and $A$ is false (true) in $F(G)$.

3.31 The refutation of $\square_{2} A \supset \square 1 \square_{2} A$, i.e., $\sim \square_{2} A \vee \square_{1} \square_{2} A$ :
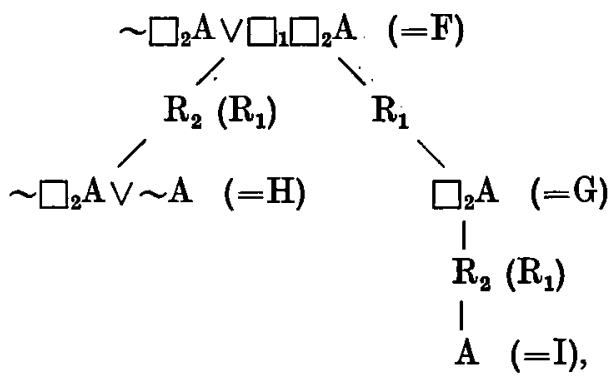

where the Hintikka collection consists of $F, G, H$ and I with $F R_{1} F, F R_{1} G, G R_{1} G$, 
G $R_{2}$ G, F $R_{2} H, F R_{1} H, H R_{2} H, H R_{1} H, G R_{2} I, G R_{1} I, I R_{1} I, I R_{2} I$ and $F R_{1} I$, and $A$ is true (false) in $H(I)$.

3.32 The refutation of $\square_{2} A \supset \square_{2} \square_{1} A$, i.e., $\sim \square_{2} A \vee \square_{2} \square_{1} A$ :

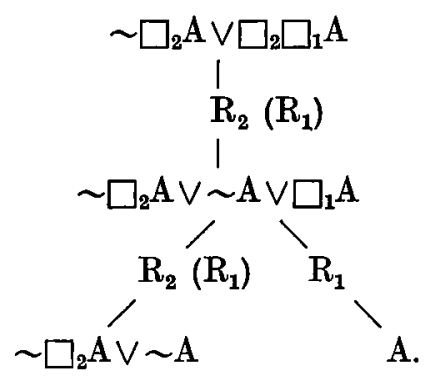

(Here as well as in what follows we shall omit the self-explanatory description of the Hintikka collection obtained and accessibility relation holding between its element formulas.)

3.41 The refutation of $\square_{1} \square_{2} A \supset \square_{1} \square_{1} A$, i.e, $\sim \square_{1} \square_{2} A \vee \square_{1} \square_{1} A$ :

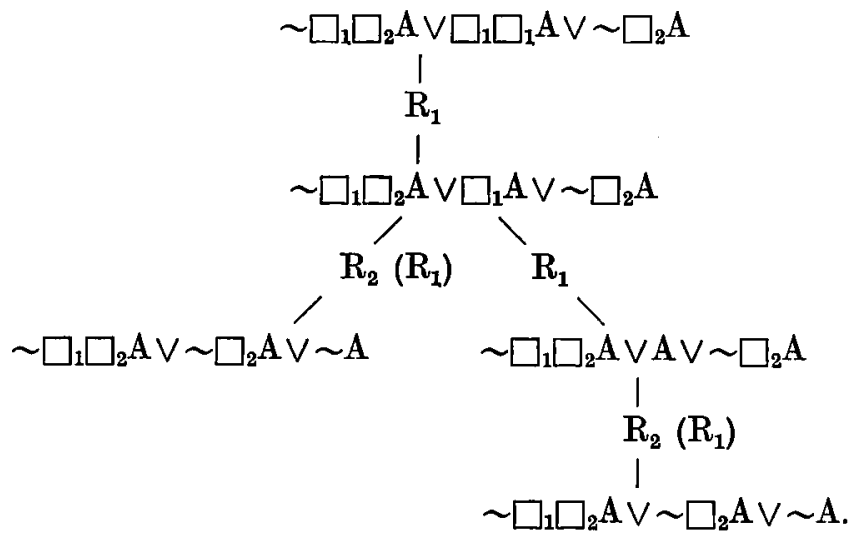

3.42 The refutation of $\square_{1} \square_{2} A \supset \square_{2} \square_{1} A$, i.e., $\sim \square_{1} \square_{2} A \vee \square_{2} \square_{1} A$ :

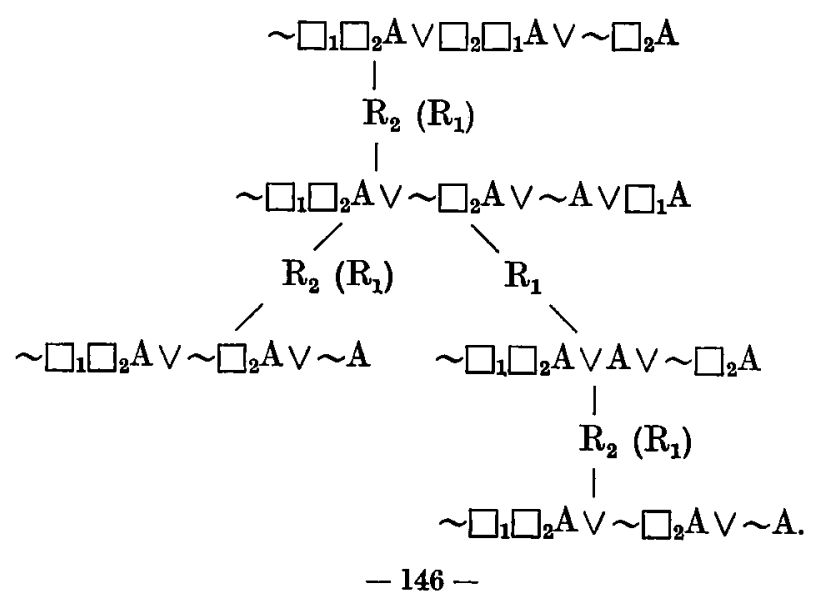


3.51 The refutation of $\square_{2} \square_{1} A \supset \square_{1} \square_{1} A$, i.e., $\sim \square_{2} \square_{1} A \vee \square_{1} \square_{1} A$ :

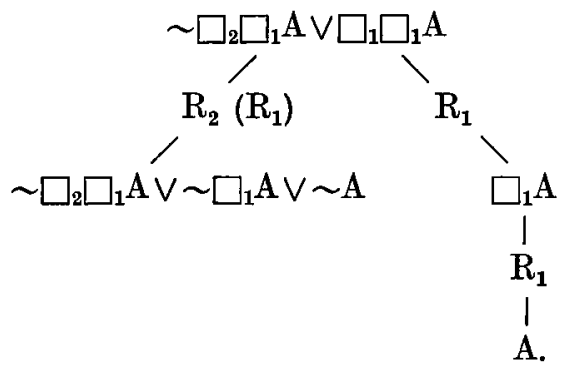

3.52 The refutation of $\square_{2} \square_{1} A \supset \square_{1} \square_{2} A$, i.e., $\sim \square_{2} \square_{1} A \vee \square_{1} \square_{2} A$ :

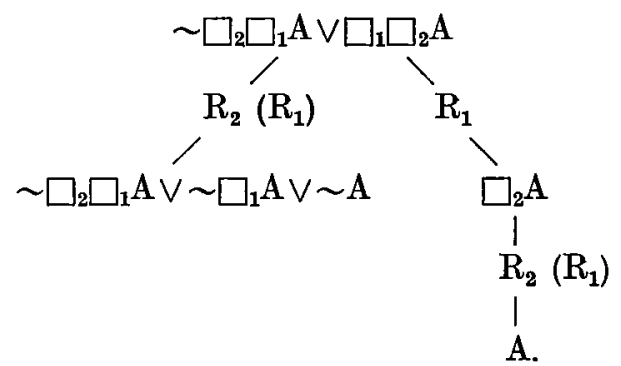

3.61 The refutation of $\square_{2} \square_{2} \mathrm{~A} \supset \square_{1} \square_{1} \mathrm{~A}$, i.e., $\sim \square_{2} \square_{2} \mathrm{~A} \vee \square_{1} \square_{1} \mathrm{~A}$ :

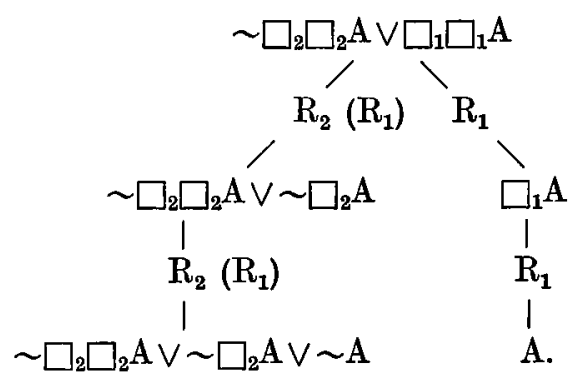

3.62 The refutation of $\square_{2} \square_{2} A \supset \square_{1} \square_{2} A$, i.e., $\sim \square_{2} \square_{2} A \vee \square_{1} \square \square_{2} A$ :

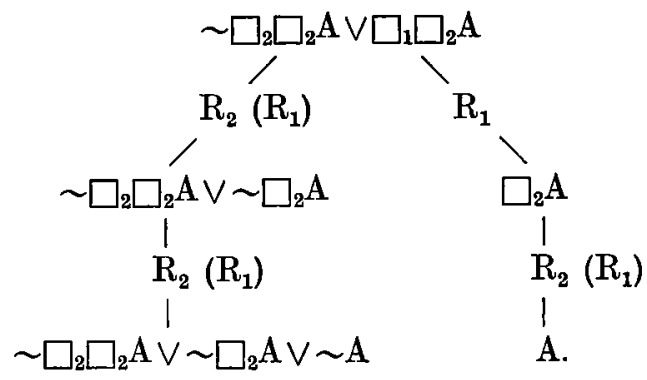


3.63 The refutation of $\square_{2} \square_{2} A \supset \square_{2} \square_{1}$ A, i.e., $\sim \square_{2} \square_{2} A \vee \square_{2} \square_{1} A$ :

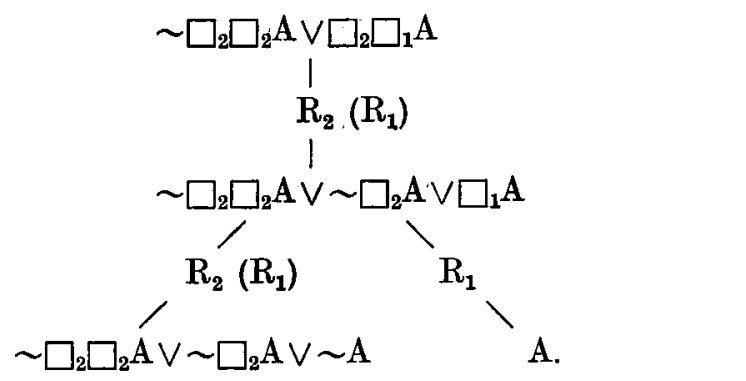

For reference we shall list up without proof all the theses of the form $\square_{\mathrm{i}} \square \mathrm{j} A$ $\supset \square_{\mathrm{k}} \square_{1} \mathrm{~A}$ with $\mathrm{i}, \mathrm{j}, \mathrm{k}$ and $\mathrm{l}$ being 1 or 2 .

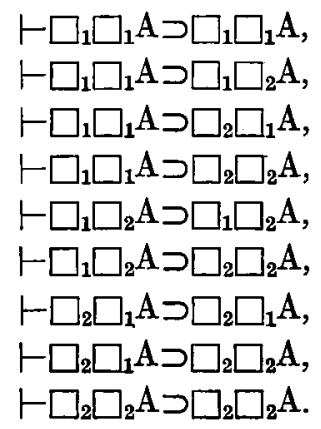

It is interesting to observe that some of the formulas of this form provable in bi-modal logic S4-S4 or T-T are not necessarily the theses of S4-DS4. In fact, $\square_{1} \square_{2} \mathrm{~A} \supset \square_{1} \square_{1} \mathrm{~A}, \square_{1} \square_{2} \mathrm{~A} \supset \square_{2} \square_{1} \mathrm{~A}, \square_{2} \square_{1} \mathrm{~A} \supset \square_{1} \square_{1} \mathrm{~A}$ and $\square_{2} \square_{2} \mathrm{~A} \supset \square_{1} \square_{2} \mathrm{~A}$ are theses of S4-S4, but not necessarily one in S4-DS4 as shown above. On the other hand, all the formulas with the forms above listed up are provable in T-T. (For this refer to Ishimoto-Watanabe [10] pp. 72-73.)

§4 Hiblert-type version In this section we shall be concerned with a Hilbert-type version of S4-DS4 and its Henkin-type completeness proof.

Since this type of formulation of modal logic and its completeness are wellknown, we shall confine ourselves to a sketch along with some preliminaries thereto. (For the Henkin-type completeness refer to Hintikka [7], Lemmon-Scott [11], Mackinson [12], Schütte [18] and Hughes-Cresswell ! [8].)

The axioms of the Hilbert-type version of S4-DS4 are grouped into:

4.11 A set of axiom schemata in terms of $\vee$ and $\sim$ sufficient to yield all the instances of tautology with the help of detachment,

4.12

4.13

$$
\begin{aligned}
& \vdash \square \square_{1} A \supset \square_{2} A, \\
& \vdash \square{ }_{1} A \supset A,
\end{aligned}
$$


$4.14 \quad \vdash \square_{2} \mathrm{~A} \supset \sim \square_{2} \sim A$, i.e., $\square_{2} \mathrm{~A} \supset \mho_{2} \mathrm{~A}$,

$4.15 \quad \vdash \square \square_{1}(\mathrm{~A} \supset \mathrm{B}) \supset\left(\square_{1} \mathrm{~A} \supset \square_{1} \mathrm{~B}\right)$;

$4.16 \quad \vdash \square_{2}(A \supset B) \supset\left(\square_{2} A \supset \square{ }_{2} B\right)$,

$4.17 \quad \vdash \square{ }_{1} \mathrm{~A} \supset \square_{1} \square_{1} \mathrm{~A}$,

$4.18 \quad-\square_{2} \mathrm{~A} \supset \square_{2} \square_{2} \mathrm{~A}$,

where A and B are ranging over (well-formed) formulas (of S4-DS4). (All these formulas were proved in $\S 1$ by the tableau method.)

The rules are detachment and necessitation for $\square_{1}$, that corresponding to $\square_{2}$ being derived from this by means of 4.12 and detachment.

It is noticed in this connection that the same logical symbols as introduced in $\S 1$, namely, $\vee, \sim, \square_{1}$ and $\square_{2}$ will remain to be employed, and other logical symbols are defined in their terms.

Lemma 4.2 (Consistency theorem) If $\mathrm{A}$ is a thesis in the Hilbert-type version of S4-DS4, then it is valid with respect to the models as defined in \$2.

The proof is carried out by induction on the length of the proof of the thesis (in the Hilbert-type version of S4-DS4). Since the proof is easily adapted from those given for T-T and S4-S4 in Ishimoto-Watanabe [10] pp. 73-75, we shall confine ourselves to the validity of axioms of the form 4.14 , which needs a different treatment.

With this in view let us assume that we are given a model $M=\left\langle G, R_{1}, R_{2}, \models\right\rangle$ such that $\Gamma \models \square_{2} \mathrm{~A}$ for a $\Gamma \in \mathrm{G}$. By 2.24 we, then, have $\forall \Delta\left(\Gamma \mathrm{R}_{2} \Delta \Rightarrow \Delta \models \mathrm{A}\right)$. On the other hand, there is a $\Lambda$ such that $\Gamma \mathrm{R}_{2} \Lambda$ by 2.15 . Wé, therefore, have $A=\mathrm{A}$, from which follows $\exists \Delta\left(\Gamma \mathrm{R}_{2} \Delta\right.$ and $\left.\Delta \nVdash \sim \mathrm{A}\right)$ in view of 2.22 . This, then, gives rise to not $\forall \Delta\left(\Gamma R_{2} \Delta \Rightarrow \Delta \models \sim A\right)$, which is nothing but $\Gamma \nvdash \square_{2} \sim \mathrm{A}$, namely, $\Gamma \models \sim$ $\square \square_{2} \sim \mathrm{A}$ by 2.22 and 2.24 .

We are next stating without proofs some lemmas, all of which are well-known in the literature and easily adapted from the case of single modality. (Consult, for example, Gresswell [1] and Hughes-Cresswell [8] pp. 155-156.)

Lemma 4.31 If $\left\{\square_{1} A_{1}, \square_{1} A_{2}, \cdots, \square_{1} A_{n}, \sim \square_{1} B\right\}$ with $1 \leq \mathrm{n}$ is consistent, then $\left\{\mathrm{A}_{1}, \mathrm{~A}_{2}, \cdots, \mathrm{A}_{\mathrm{n}}, \sim \mathrm{B}\right\}$ is consistent.

Lemma 4.32 If $\sim \square_{1} \mathrm{~B}$ is consistent, then $\sim \mathrm{B}$ is consistent.

Lemma 4.33 If $\left\{\square_{2} \mathrm{~A}_{1}, \square_{2} \mathrm{~A}_{2}, \cdots, \square_{2} \mathrm{~A}_{\mathrm{n}}, \sim \mathrm{B}\right\}$ with $1 \leq \mathrm{n}$ is consistent, then $\left\{\mathrm{A}_{1}, \mathrm{~A}_{2}, \cdots, \mathrm{A}_{\mathrm{n}} \sim \mathrm{B}\right\}$ is consistent.

Lemma 4.34 If $\sim \square_{2} \mathrm{~B}$ is consistent, then $\sim \mathrm{B}$ is consistent.

(Lemma $4.32(4.34)$ is the case of $n=0$ in Lemma 4.31 (4.33).)

We are also stating a lemma, which is peculiar to S4-DS4.

Lemma 4.35 If $\left\{\square_{2} \mathrm{~A}_{1}, \square_{2} \mathrm{~A}_{2}, \cdots, \square_{2} \mathrm{~A}_{\mathrm{n}}\right\}$ with $1 \leq \mathrm{n}$ is consistent, then $\left[\mathrm{A}_{1}\right.$, $\left.\mathrm{A}_{2}, \cdots, \mathrm{A}_{\mathbf{n}}\right\}$ is consistent.

Suppose $\left\{A_{1}, A_{2}, \cdots, A_{n}\right\}$ be not consistent. We, then, have $\vdash\left(A_{1} \wedge A_{2} \wedge \cdots\right.$ $\left.\wedge A_{n}\right) \supset$ (negation of a tautology). From this follows $\vdash\left(\square_{2} A_{1} \wedge \square_{2} A_{2} \wedge \cdots \wedge \square_{2} A_{n}\right)$ 
$\supset \square_{2}$ (negation of a tautology) by the necessitation for $\square_{2}$ and 4.16, which in turn gives rise to $\vdash\left(\square_{2} A_{1} \wedge \square_{2} A_{2} \wedge \cdots \wedge \square_{2} A_{n}\right) \supset \sim \square_{2} \sim$ (negation of a tautology), i.e., $\vdash\left(\square_{2} \mathrm{~A}_{1} \wedge \square_{2} \mathrm{~A}_{2} \wedge \cdots \wedge \square_{2} \mathrm{~A}_{\mathrm{n}}\right) \supset \sim \square_{2}$ tautology by 4 .14. Since $\vdash \square_{2}$ tautology by 4.11 and the necessitation for $\square_{2}$, we have $\vdash \sim\left(\square_{2} \mathrm{~A}_{1} \wedge \square_{2} \mathrm{~A}_{2} \wedge \cdots \wedge \square_{2} \mathrm{~A}_{n}\right)$, namely, $\left\{\square_{2} A_{1}, \square_{2} A_{2}, \cdots, \square_{2} A_{n}\right\}$ is not consistent.

We are now in a position to give another definition of a Hintikka collection, this time, in a way less constructive than its correspondent introduced in $\S 2$. The Hintikka collection here to be introduced is different from the former one in that the members of the collection are (necessarily maximally) consistent sets of formulas of S4-DS4.

Definition 4.4 A Hintikka collection is a non-empty collection of consistent sets $\mathrm{G}$ of formulas satisfying for any $\Gamma \in \mathrm{G}$ :

$$
\begin{array}{ll}
4.41 & \mathrm{~A} \vee \mathrm{B} \in \Gamma \Leftrightarrow \mathrm{A} \in \Gamma \text { or } \mathrm{B} \in \Gamma, \\
4.42 & \sim(\mathrm{A} \vee \mathrm{B}) \in \Gamma \Leftrightarrow \sim \mathrm{A} \in \Gamma \text { and } \sim \mathrm{B} \in \Gamma, \\
4.43 & \sim \sim \mathrm{A} \in \Gamma \Leftrightarrow \mathrm{A} \in \Gamma, \\
4.44 & \text { not } \mathrm{A} \in \Gamma \Rightarrow \mathrm{A} \in \Gamma, \\
4.45 & \sim \square_{1} \mathrm{~A} \in \Gamma \Leftrightarrow \exists \Delta\left(\Gamma \mathrm{R}_{1} \Delta \text { and } \sim \mathrm{A} \in \Delta\right), \\
4.46 & \sim \square_{2} \mathrm{~A} \in \Gamma \Leftrightarrow \exists \Delta\left(\Gamma \mathrm{R}_{2} \Delta \text { and } \sim \mathrm{A} \in \Delta\right), \\
4.47 & \exists \Delta \Gamma \mathrm{R}_{2} \Delta,
\end{array}
$$

where the accesibility relations $\mathrm{R}_{1}$ and $\mathrm{R}_{2}$ are respectively defined as:

$$
\begin{aligned}
& \Gamma \mathrm{R}_{1} \Delta \Leftrightarrow \forall \mathrm{A}\left(\square_{1} \mathrm{~A} \in \Gamma \Rightarrow \mathrm{A} \in \Delta\right), \\
& \Gamma \mathrm{R}_{2} \Delta \Leftrightarrow \forall \mathrm{A}\left(\square_{2} \mathrm{~A} \in \Gamma \Rightarrow \mathrm{A} \in \Delta\right) .
\end{aligned}
$$

On the basis of the Hintikka collection we define a satisfaction relation $\models$ for any $\Gamma \in G$ and atomic formula $A$ as $A \in \Gamma$, which is, then, extended (uniquely and consistently) to any $\Gamma(\epsilon \mathrm{G})$ and formula by way of 2.21-2.24.

Lemma 4.5 The model $\mathrm{M}=\left\langle\mathrm{G}, \mathrm{R}_{1}, \mathrm{R}_{2}, \models\right\rangle$ thus defined on the basis of a Hintikka collection satisfies the following conditions:

$$
\begin{aligned}
4.51 \quad \mathrm{~A} \in \Gamma & \Leftrightarrow \Gamma \models \mathrm{A}, \\
4.52 & \sim \mathrm{A} \in \Gamma \Leftrightarrow \Gamma \not \models \mathrm{A}, \text { i.e., } \Gamma \models \sim \mathrm{A}
\end{aligned}
$$

for any $\Gamma(\epsilon \mathrm{G})$ and $\mathrm{A}$. (4.51 and 4.52 are equivalent to each other.)

It is noticed that if the given Hintikka collection consists of all the maximally consistent sets (of formulas) as it does necessarily, then the model $M$ constitutes a model of S4-DS4 with $R_{1}$ and $R_{2}$ satisfying 2.12-2.15. Now the Lemma is proved simultaneously by induction on the length of $A$.

The basis is straightforward from the definition of the satisfaction relation and the consistency of $\Gamma(\in \mathrm{G})$.

Induction steps are taken care of in the following way: 


$$
\begin{aligned}
& \mathrm{A}_{1} \vee \mathrm{A}_{2} \in \Gamma \Leftrightarrow \cdot \mathrm{A}_{1} \in \Gamma \text { or } \mathrm{A}_{2} \in \Gamma \text {. } \\
& \Leftrightarrow \cdot \Gamma \models \mathrm{A}_{1} \text { or } \Gamma \models \mathrm{A}_{2} \cdot \Leftrightarrow \Gamma \models \mathrm{A}_{1} \vee \mathrm{A}_{2} \text {, } \\
& \sim\left(\mathrm{A}_{1} \vee A_{2}\right) \in \Gamma \Leftrightarrow \cdot \sim \mathrm{A}_{1} \in \Gamma \text { and } \sim \mathrm{A}_{2} \in \Gamma \text {. } \\
& \Leftrightarrow \cdot \Gamma \nVdash A_{1} \text { and } \Gamma \nvdash A_{2} \text {. } \\
& \Leftrightarrow \operatorname{not}\left(\Gamma \models \mathrm{A}_{1} \text { or } \Gamma \models \mathrm{A}_{2}\right) \Leftrightarrow \Gamma \not \models \mathrm{A}_{1} \vee \mathrm{A}_{2} \text {, } \\
& \sim \mathrm{A}_{1} \in \Gamma \Leftrightarrow \text { not } \mathrm{A}_{1} \in \Gamma \Leftrightarrow \Gamma \not \models \mathrm{A}_{1} \Leftrightarrow \Gamma \models \sim \mathrm{A}_{1} \\
& \sim \sim \mathrm{A}_{1} \in \Gamma \Leftrightarrow \mathrm{A}_{1} \in \Gamma \Leftrightarrow \Gamma \models \mathrm{A}_{1} \Leftrightarrow \Gamma \not \models \sim \mathrm{A}_{1} \text {, } \\
& \square_{1} \mathrm{~A}_{1} \in \Gamma \Leftrightarrow \forall \Delta\left(\Gamma \mathrm{R}_{1} \Delta \Rightarrow \mathrm{A}_{1} \in \Delta\right) \\
& \Leftrightarrow \forall \Delta\left(\Gamma \mathrm{R}_{1} \Delta \Rightarrow \Delta \models \mathrm{A}_{1}\right) \Leftrightarrow \Gamma \models \square_{1} \mathrm{~A}_{1}, \\
& \sim \square_{1} \mathrm{~A}_{1} \in \Gamma \Leftrightarrow \exists \Delta\left(\Gamma \mathrm{R}_{1} \Delta \text { and } \sim \mathrm{A}_{1} \in \Delta\right) \\
& \Leftrightarrow \exists \Delta\left(\Gamma \mathrm{R}_{1} \Delta \text { and } \Delta \not K \mathrm{~A}_{1}\right) \Leftrightarrow \Gamma \not \models \square_{1} \mathrm{~A}_{1} \text {, } \\
& \square_{2} \mathrm{~A}_{1} \in \Gamma \Leftrightarrow \forall \Delta\left(r \mathrm{R}_{2} \Delta \Rightarrow \mathrm{A}_{1} \in \Delta\right) \\
& \Leftrightarrow \forall \Delta\left(\Gamma \mathrm{R}_{2} \Delta \Rightarrow \Delta \models \mathrm{A}_{1}\right) \Leftrightarrow \Gamma \models \square_{2} \mathrm{~A}_{1}, \\
& \sim \square_{2} \mathrm{~A}_{1} \in \Gamma \Leftrightarrow \exists \Delta\left(\Gamma \mathrm{R}_{2} \Delta \text { and } \sim \mathrm{A}_{1} \in \Delta\right) \\
& \Leftrightarrow \exists \Delta\left(\Gamma \mathrm{R}_{2} \Delta \text { and } \Delta \not \mathrm{A}_{1}\right) \Leftrightarrow \Gamma \not \models \square_{2} \mathrm{~A}_{1} \text {, }
\end{aligned}
$$

where use is made of the properties of the Hintikka collection, in particular,

$$
\begin{aligned}
& \square_{1} \mathrm{~A} \in \Gamma \Leftrightarrow \forall \Delta\left(\Gamma \mathrm{R}_{1} \Delta \Rightarrow \mathrm{A} \in \Delta\right), \\
& \square_{2} \mathrm{~A} \in \Gamma \Leftrightarrow \forall \Delta\left(\Gamma \mathrm{R}_{2} \Delta \Rightarrow \mathrm{A} \in \Delta\right),
\end{aligned}
$$

which are forthcoming from $4.44,4.45$ and 4.46 .

Now we construct the collection of all the maximally consistent sets of formulas in S4-DS4.

This non-empty collection constitutes a Hintikka collection meeting all the requirements for a Hintikka collection, of which $4.41-4.44$ are trivially satisfied. 4.45 (4.46), on the other hand, is taken care of by Lemma 4.31 (4.33), and the proofs are easily adapted from the corresponding ones given, for example, in Ishimoto-Watanabe [10] p. 77 for T-T and S4-S4. It is only noticed that the set \{B: $\left.\square_{1} \mathrm{~B} \in \Gamma\right\} \quad\left(\left\{\mathrm{B}: \square_{\mathbf{2}} \mathrm{B} \in \Gamma\right\}\right)$, which plays an important role in the proof of 4.45 (4.46), is never empty, since $\square_{1}$ tautology $\left(\square_{2}\right.$ tautology) is a thesis of S4-DS4, therefore, belonging to every maximally consistent set (of formulas). We, thus, do not need Lemma 4.32 (4.34 for the proof of 4.45 (4.46). (Consult also HughesCresswell [8] and Cresswell [1].)

Lastly with a view to proving 4.47 let us assume that we are given a miximally consistent set $\Gamma$ (of formulas). We define a set $\mathrm{E}=\left\{\mathrm{B}: \square_{2} \mathrm{~B} \in \Gamma\right\}$, which is not empty because of the thesishood of a formula of the form $\square_{2} \mathrm{~B}$ as above remarked. The set $\mathbf{E}$ (of formulas) thus defined is consistent. In fact, if $\mathrm{E}$ were not consistent, there would be a finite set $\left\{B_{1}, B_{2}, \cdots, B_{n}\right\}(1 \leq n)$ with $\square_{2} B$ 's belonging to $\Gamma$, which is already inconsistent. In view of Lemma 4.35 from this would follow the inconsistency of $\left\{\square_{2} B_{1}, \square_{2} B_{2}, \cdots, \square_{2} B_{n}\right\}$ against the consistency of $\Gamma$.

The set $\mathrm{E}$ is, then, extended to a maximally consistent set $\Delta$ (of formulas), 
which is a looked-for element of $\mathrm{G}$ with $\Gamma \mathrm{R}_{2} \Delta$.

Now suppose A be not provable. Since $\{\sim A\}$ is consistent, it is extended to a maximally consistent set $\Gamma$ (of formulas), which contains $\sim \mathrm{A}$ as an element. By 4.52 $\Gamma \nvdash \subset \mathrm{A}$ in the model of S4-DS4 defined on the basis of the Hintikka collection consisting of all the maximally consistent sets (of formulas).

This completes the Henkin-type proof of the completeness of the Hilbert-type version of S4-DS4 with respect to the semantics as introduced in $\$ 2$.

This in combination with the consistency theorem for the version gives rise to the consistency and completeness theorem for the Hilbert-type version of S4-DS4 with respect to the semantics. Nevertheless, if we take into consideration the proof of completeness as above sketched, it is strengthened to a theorem wellknown in the literature with respect to normal modal logies with one modal operator. (cf. Cresswell [1])

Theorem 4.6 A is a thesis of S4-DS4 iff A is valid in the model defined on the basis of the Hintikka collection consisting of all the maximally consistent sets (of formulas).

As a corollary we prove the compactaness theorem for S4-DS4.

Corollary 4.61 (Compactness theorem) If $\mathrm{E}$ is a consistent set (of formulas), then there is a model (of S4-DS4) $\mathrm{M}=\left\langle\mathrm{G}, \mathrm{R}_{1}, \mathrm{R}_{2}, \models\right\rangle$ and a $\Gamma \in \mathrm{G}$ such that $\Gamma \models \mathrm{A}$ for every $\mathrm{A} \in \mathrm{E}$.

The given $\mathrm{E}$, which is assumed to be consistent, is extended to a maximally consistent set (of formulas) belonging to $G$, which is a constitutent of the model defined on the basis of the Hintikka collection of all the maximally consistent sets (of formulas). By 4.51, we, then, have $\Gamma \models \mathrm{A}$ for every $\mathrm{A} \in \mathrm{E}$.

It is noticed in passing that the separation theorem (Corollary 2.9) is forthcoming, this time, semantically.

With this in view let us assume that $A$ be a thesis of S4-DS4 without involving $\square_{2}\left(\square_{1}\right)$. In other words A is supposed to be a formula of S4 (DS4). Suppose, if possible, that A be not provable in S4 (DS4). By the analogue of Theorem 4.6 for S4 (DS4) there is a model $M=\langle G, R, \models\rangle$ of $S 4$ (DS4) defined on the basis of the Hintikka collection of all the maximally consistent. sets (of formulas) with $\mathrm{A}$ falsified in a $\Gamma(\in \mathrm{G})$.

Now in terms of the model of S4 (DS4) we define a model $M_{1}=\left\langle G, R_{1}, R_{2}, \models\right\rangle$ such that $R_{1}=R_{2}=R$, which constitutes a model of S4-DS4. (For obtaining a model of S4-DS4 from that of DS4 we need to extend $R_{1}$ and make it reflexive.) As is easily seen $A$ would be false in the $\Gamma(\epsilon G)$ against our hypothesis.

This completes the model-theoretic proof of the separation theorem.

Before concluding this section it is remarked that, the equivalence of two versions of S4-DS4, namely, that developed in \$1 and.its Hilbert-type correspondent is forthcoming right away from the consistency and completeness theorem 
separatedly proved of these two formulations of S4-DS4.

This kind of equivalence theorem, which was here demonstrated semantically, is usually proved by way of the so-called cut elimination theorem, which in the formulation as rendered in $\S 1$ is understood to be the eliminability of the following reduction rule:

$$
\operatorname{cut} \frac{\mathbf{F}[+] \vee G[-]}{\mathbf{F}\left[\mathbf{A}_{+}\right] \mid \mathrm{G}\left[\mathbf{A}_{+}\right]},
$$

where $\mathbf{A}$ is the cut formula of the cut application. (This form of cut could be called analytic cut.)

Lemma 4.7 Given a model $\mathrm{M}=\left\langle\mathrm{G}, \mathrm{R}_{1}, \mathrm{R}_{2}, \models\right.$ of $\mathrm{S} 4-\mathrm{DS} 4$,

$$
\begin{aligned}
& r \models \mathrm{F}\left[\mathrm{A}_{+}\right] \Leftrightarrow \Gamma \models \mathrm{F}[\quad+] \vee \mathrm{A}, \\
& \Gamma \models \mathrm{G}\left[\mathrm{A}_{-}\right] \Leftrightarrow \Gamma \models \mathrm{G}[\quad-] \vee \sim \mathrm{A},
\end{aligned}
$$

for any $\Gamma \in \mathrm{G}$.

These two assertions are proved simultaneously by induction on the number of procedures employed for specifying $A$ as a positive (negative) part of $F\left[A_{+}\right]$(G[A-]).

The basis being straightforward we are proceeding to induction steps, which are taken care of as follows:

$$
\begin{aligned}
\Gamma \models \mathrm{F}\left[\mathrm{A}_{+}\right] & \Leftrightarrow \Gamma \models \mathrm{F}_{1}\left[\mathrm{~A} \vee \mathrm{B}^{+}\right] \text {or } \mathrm{F}_{1}\left[\mathrm{~B} \vee \mathrm{A}_{+}\right] \\
& \Leftrightarrow \Gamma \models=\mathrm{F}_{1}[\quad+] \vee(\mathrm{A} \vee \mathrm{B}) \\
& \Leftrightarrow \Gamma \models\left(\mathrm{F}_{1}[\quad+] \vee \mathrm{B}\right) \vee \mathrm{A} \Leftrightarrow \Gamma \models \mathrm{F}[\quad+] \vee \mathrm{A}, \\
\Gamma \models \mathrm{F}\left[\mathrm{A}_{+}\right] & \Leftrightarrow \Gamma \models \mathrm{F}_{1}\left[\sim \mathrm{A}_{-}\right] \Leftrightarrow \Gamma \models \mathrm{F}_{1}[\quad-] \vee \sim \sim \mathrm{A} \\
& \Leftrightarrow \Gamma \models \mathrm{F}[+] \vee \mathrm{A}, \\
\Gamma \models \mathrm{G}\left[\mathrm{A}_{-}\right] & \Leftrightarrow \Gamma \models \mathrm{G}_{1}\left[\sim \mathrm{A}_{+}\right] \Leftrightarrow \Gamma \models \mathrm{G}_{1}[\quad+] \vee \sim \mathrm{A} \\
& \Leftrightarrow \Gamma \models \mathrm{G}[\quad-] \vee \sim \mathrm{A},
\end{aligned}
$$

where use is made of Definition 1.2, namely, the definition of the procedures of removing a formula from another.

Lemma 4.8 If $\mathrm{F}\left[\mathrm{A}_{+}\right]$and $\mathrm{G}[\mathrm{A}]$ are valid, then $\mathrm{F}\left[{ }_{+}\right] \vee \mathrm{G}\left[{ }_{-}\right]$. is also valid.

In other words the validity is preserved by the application of cut in the usual sense of the word.

Suppose $F\left[A_{+}\right]$and $G\left[A_{-}\right]$be both valid. Further, let us assume, if possible, $\mathbf{F}[+] \vee G\left[{ }_{-}\right]$be not valid. This means that there would be a model $M=\left\langle G, R_{1}\right.$, $\mathrm{R}_{2}, \models>$ such that $\Gamma \nvdash \mathrm{F}\left[{ }_{+}\right] \vee \mathrm{G}\left[{ }_{-}\right]$for a $\Gamma(\in \mathrm{G})$. By $2.21 \Gamma \nvdash \mathrm{F}\left[{ }_{+}\right]$and $\Gamma \nvdash \mathrm{G}\left[{ }_{-}\right]$.

By the hypothesis $\Gamma \models\left[\mathrm{A}_{+}\right]$and $\Gamma \models \mathrm{G}\left[\mathrm{A}_{-}\right]$, which respectively give rise to $\Gamma \models \mathrm{F}\left[{ }_{+}\right] \vee \mathrm{A}$ and $\Gamma \models \mathrm{G}[-] \vee \sim \mathrm{A}$ in view of Lemma 4.7 just proved. Since $\Gamma \nvdash \mathrm{F}\left[{ }_{+}\right]$and $\Gamma \nvdash \mathrm{G}[-]$, we have simultaneously $\Gamma \models \mathrm{A}$ and $\Gamma \models \sim \mathrm{A}$ by 2.21 , namely, $\Gamma \models \mathrm{A}$ and $\Gamma \nvdash \mathrm{A}$ by 2.22 , a contradiction.

Theorem 4.9 (Cut elimination theorem) If a formula is a thesis in the tableau method adjoined with cut, then it is already provable in the tableau method without cut. 
Suppose a formula be provable by the talbeau method involving cut. Now every end point of the tableau is valid being of the form $\mathbf{F}\left[\mathbf{A}_{+}, \mathbf{A}_{-}\right]$. Its validity is forthcoming from its equivalence to that of $\mathrm{F}[+,-] \vee \mathrm{A} \vee \sim \mathrm{A}$ by Lemma 4.7.

The reduction rules including cut, on the other hand, preserves the validity if applied in the reverse direction. The case of cut has been taken care of by Lemma 4.8, while the remaining cases do not present any difficulties.

From this follows the validity of the given formula, which in turn yields the thesishood of the formula by the tableau method without cut in view of the completeness theorem, namely, Lemma 2.7.

This completes the proof of Theorem 4.9.

In the paper to follow we wish to generalize the results here obtained to other bi-modal logics. We shall also incorporate our method to modal logics originating from Fitch [2], where a part of many-world semantics is integrated into object langauge. (For this type of logics refer to Fitting [5].)

\section{Bibliography}

[1] Cresswell, M.J., Frames and Models in Modal Logic, (Unpublished).

[2] Fitch, Frederic B., Tree proofs in modal logic (abstract) The Journal of Symbolic Logic, Vol. 31 (1966), p. 152.

[3] Fitting, M., Intuitionistic Logic, Model Theory and Forcing, Amsterdam-London, 1969.

[4] Fitting, M., Logics with several modal operators, Theoria, Vol. 35, 1969.

[5] Fitting, M., Tableau Methods of Proof for Modal Logics, Notre Dame Journal of Formal Logic, Vol. 13, 1972, pp. 237-247.

[6] Hintikka, J., Knowledge and Belief, Ithaca, New York, 1962.

[7] Hintikka, J. The models of modality, Modal and Many-valued Logics, Acta Philosphica Fennica, 1963

[8] Hughes, G.E. \& Cresswell, M.J., An Introduction to Modal Logic, 1968.

[9] Ishimoto, A. \& Fujikawa, Y., On Some Bi-Modal Predicate Calculi, Bulletin of the Tokyo Institute of Technology, No. 100, pp. 129-141.

[10] Ishimoto, A. \& Watanabe, Yo, Some Bi-Modal Propositional Logies and Their Completeness, ibid., No. 124, 1974, pp. 63-79.

[11] Lemmon, E.J. \& Scott, D., Intensional Logic, Preliminary draft of initial chapters by E.J. Lemmon, (mimeographed), 1966

[12] Makinson, D.C., On Some Completeness Thorems in Modal Logic, Zeitschrift für Mathematische Logik und Grundlagen der Mathematik, Vol. 12, 1966.

[13] Ono, H., On some intuitionistic modal logics, Publications of the Research Institute for Mathematical Sciences, Kyoto University, Vol. 13, No. 3, 1977, pp. 687-722.

[14] Rubin, J., Bi-Modal Logic, Double Closure Algebra, and Hilbert Space, Zeitschrift für Mathematische Logik und Grundlagen der Mathematik, Vol. 8, 1962.

[15] Schütte, K., Aussagenlogische Grundeigenschaften Formaler System, Logica, Studia Paul Bernays Dedicata, 1952.

[16] Schütte, K., Ein System der verknüpfenden Schliessens, Archiv für Mathematische Logik und Grundlagenforschung, Vol. 2, 1956.

[17] Schütte, K., Beweistheorie, Berlin - Göttingen - Heidelberg, 1960.

[18] Schütte, K., Vollständige Systeme modaler und intuitionistischer Logik, Berlin Heidelberg - New York, 1968. 
[19] Schütte, K., Proof Theory, Berlin-Heidelberg-New York, 1977.

[20] Smullyan, R.M., First-Order Logic, Berlin-Heidelberg-New York, 1968.

[21] Uchida, T., Gentzen-Schütte-type Formulation of the Logic of 'Knowledge and Belief', Philosophy of Science, No. 8, 1975 (in Japanese). 